\title{
Continuous Glucose Monitoring in 2015
}

\author{
Tadej Battelino ${ }^{1,2}$ and Bruce W. Bode ${ }^{3}$
}

\section{Introduction}

Diabetes Research in Children Network (DirecNet) demonstrated decreased gray matter volume related to glycemic load and glucose variability (1) and a decrease in longitudinal development of gray matter volume related to hyperglycemia and glucose variability (2) in children with type 1 diabetes (T1D). These important data added a new noteworthy angle to the spectrum of chronic complications of T1D in children rendering the use of continuous glucose monitoring (CGM) for increasing the time spent in near-normoglycemia (3) considerably more relevant. For some surprisingly and for many quite expectedly, hyperglycemia (not hypoglycemia) and, importantly, glucose variability were associated with damage to the developing brain. These findings were independently confirmed in a study in middle-aged adults (4). Moreover, several recent studies confirmed the association between glucose variability and chronic complications in people with type 2 diabetes (T2D), putting more focus on CGM also in this population. More data on new implantable sensors used for up to 90 days demonstrated an important development that may increase the acceptability of CGM devices.

\section{Key Articles Reviewed for this Article \\ Continuous glucose monitoring in people with diabetes: the randomized controlled Glucose Level Awareness in Diabetes Study (GLADIS) \\ New JP ${ }^{l}$, Ajjan $R^{2}$, Pfeiffer AFH ${ }^{3}$, Freckmann $G^{4}$ \\ Diabetic Medicine 2015; 32: 609-17 \\ Effect of lipohypertrophy on accuracy of continuous glucose monitoring in patients with type 1 diabetes \\ DeSalvo $D J^{l}$, Maahs $D M^{2}$, Messer $L^{2}$,Wadwa $R P^{2}$, Payne $S^{l}$, Ly TT ${ }^{1,3}$, Buckingham BA ${ }^{l}$ \\ Diabetes Care 2015. [Epub ahead of print] DOI 10.2337/dc15-1267 \\ Association between blood glucose variability and coronary plaque instability in patients with acute coronary syndromes \\ Okada $K^{l}$, Hibi $K^{l}$, Gohbara $M^{l}$, Kataoka $S^{l}$, Takano $K^{l}$, Akiyama $E^{l}$, Matsuzawa $Y^{l}$, Saka $K^{1}$, Maejima $N^{1}$, Endo $M^{l}$, Iwahashi $N^{1}$, Tsukahara $K^{l}$, Kosuge $M^{1}$, Ebina $T^{l}$, Fitzgerald $P^{2}{ }^{2}$, Honda $Y^{2}$, Umemura $S^{3}$, Kimura $K^{1}$ \\ Cardiovasc Diabetol 2015; 14: 111 \\ Effect of daily glucose fluctuation on coronary plaque vulnerability in patients pre-treated with lipid-lowering therapy: a prospective observational study \\ Kuroda $M^{l}$, Shinke $T^{l}$, Sakaguchi $K^{2}$, Otake $H^{l}$, Takaya $T^{l}$, Hirota $Y^{2}$, Sugiyama $D^{3}$, Nakagawa $M^{l}$, Hariki $H^{l}$, Inoue $T^{l}$, Osue $T^{l}$, Taniguchi $Y^{l}$, Iwasaki $M^{l}$, Nishio $R^{l}$, Kinutani $H^{1}$, Konishi $A^{1}$, Hiranuma $N^{1}$, Takahashi $H^{1}$, Terashita $D^{l}$, Hirata $K^{1}$ \\ JACC Cardiovasc Interv 2015; 8: 800-11}

${ }^{1}$ UMC-University Children's Hospital ${ }^{2}$ Faculty of Medicine, University of Ljubljana, Slovenia

${ }^{3}$ Atlanta Diabetes Associates, Atlanta, GA. 
Glycemic variability determined by continuous glucose monitoring system predicts left ventricular remodeling in patients with a first ST-segment elevation myocardial infarction

Gohbara $M^{l}$, Iwahashi $N^{l}$, Kataoka $S^{1}$, Hayakawa $Y^{2}$, Sakamaki $K^{3}$, Akiyama $E^{l}$, Maejima $N^{I}$, Tsukahara $K^{1}$, Hibi $K^{1}$, Kosuge $M^{I}$, Ebina $T^{l}$, Umemura S, Kimura $K^{l}$

Circ J 2015; 79: 1092-99

Correlation of continuous glucose monitoring profiles with pregnancy outcomes in nondiabetic women

Sung $J F^{l}$, Kogut $E A^{2}$, Lee $H C^{3}$, Mannan $J L^{4}$, Navabi $K^{5}$, Taslimi $M M^{6}$, El-Sayed $Y Y^{6}$

Amer J Perinatol 2015; 32: 461-68

Routine use of continuous glucose monitoring in 10,501 people with diabetes mellitus

Battelino $\mathrm{T}^{1,2}$, Liabat $\mathrm{S}^{3}$, Veeze $\mathrm{HJ}^{4}$, Castaneda $\mathrm{J}^{5}$, Arrieta $\mathrm{A}^{5}$, Cohen $\mathrm{O}^{6}$

Diabet Med June 4, 2015. [Epub ahead of print] DOI 10.1111/dme.12825

Accuracy of two continuous glucose monitoring systems: a head-to-head comparison under clinical research centre and daily life conditions

Kropff $J^{1}$, Bruttomesso $D^{2}$, Doll $W^{3}$, Farret $A^{4}$, Galasso $S^{2}$, Luijf $Y^{1}$, Mader $J K^{3}$, Place $\mathrm{J}^{4}$, Boscari $F^{2}$, Pieber $\mathrm{TR}^{3}$, Renard $\mathrm{E}^{4}$, DeVries $\mathrm{JH}^{l}$

Diabetes Obesity and Metabolism 2015; 17: 343-49

A clinical trial of the accuracy and treatment experience of the Dexcom G4 Sensor (Dexcom G4 System) and Enlite Sensor (Guardian REAL-Time System) tested simultaneously in ambulatory patients with type 1 diabetes

Matuleviciene $V^{1}$, Joseph $\mathrm{JI}^{2}$, Andelin $\mathrm{M}^{3}$, Hirsch $\mathrm{IB}^{4}$, Attvall $S^{1}$, Pivodic $A^{5}$, Dahlqvist $S^{3}$, Klonoff $D^{6}$, Haraldsson $B^{1}$, Lind $M^{1,3}$

Diabetes Technol Ther 2014; 16: 759-67

The performance and usability of a factory-calibrated flash glucose monitoring system

Bailey $T^{l}$, Bode $B W^{2}$, Christiansen $M P^{3}$, Klaff $L J^{4}$, Alva $S^{5}$

Diabetes Technol Ther July 14, 2015. [Epub ahead of print] DOI 10.1089/dia.2014.0378

Long-term home study on nocturnal hypoglycemic alarms using a new fully implantable continuous glucose monitoring system in type 1 diabetes

Wang $X^{1}$, Ioacara $S^{2,3}$, DeHennis $A^{l}$

Diabetes Technol Ther July 15, 2015. [Epub ahead of print] DOI 10.1089/dia.2014.0375

Continuous glucose monitoring in people with diabetes: the randomized controlled Glucose Level Awareness in Diabetes Study (GLADIS)

New $J P^{1}$, Ajjan $R^{2}$, Pfeiffer AFH ${ }^{3}$, Freckmann $G^{4}$

${ }^{1}$ Department of Diabetes, Salford Royal NHS Foundation

Trust, Salford, UK; ${ }^{2}$ Division of Cardiovascular and Diabetes Research, The LIGHT Laboratories, University of Leeds and St James University Hospital, Leeds, UK; ${ }^{3}$ Department of Endocrinology, Diabetes and Nutrition, Charité University Medical School, Berlin, Germany; ${ }^{4}$ Institut für Diabetes-Technologie Forschungs und Entwicklungsgesellschaft $\mathrm{mbH}$ an der Universität Ulm, Ulm, Germany

Diabetic Medicine 2015; 32: 609-17
Aims

To evaluate continuous glucose monitoring, with or without an alarm function, by comparing it to self-monitoring of blood glucose in insulin-treated individuals with diabetes.

\section{Methods}

A total of 160 patients with T1D or T2D, on multiple daily insulin injections or continuous subcutaneous insulin infusion, were enrolled in a 100-day, randomized controlled study conducted at four European centers. Participants were randomized after a masked 20-day period by permuted block randomization to self-monitoring of blood glucose (SMBG) $(\mathrm{n}=48)$, CGM without alarms $(\mathrm{n}=48)$, or CGM with alarms $(n=49)$. Both CGM groups used FreeStyle Navigator 
Continuous Glucose Monitoring System device (Abbott Diabetes Care, Maidenhead, UK). The primary outcome was the difference in time spent outside a glucose target of 3.9$10.0 \mathrm{mmol} / \mathrm{L}(70-180 \mathrm{mg} / \mathrm{dL})$ during days $80-100$ in the SMBG control group as compared to CGM without alarms group.

\section{Results}

Time spent outside the glucose target was $10.6 \mathrm{~h} /$ day for the SMBG group, $9.9 \mathrm{~h} /$ day for the CGM without alarms group, and $9.7 \mathrm{~h}$ /day for the CGM with alarms group (nonsignificant, $\mathrm{P}=0.18$ and 0.08 compared with CGM without and with alarms, respectively). The CGM with alarms group spent less time in hypoglycemia $(<3.9 \mathrm{mmol} / \mathrm{L}[<70 \mathrm{mg} /$ $\mathrm{dL}])$ compared with the SMBG group $(1.0 \mathrm{~h} /$ day and $1.6 \mathrm{~h} /$ day, respectively; $95 \% \mathrm{CI}-1.2$ to $-0.1 ; \mathrm{P}=0.030)$. Among those treated with continuous subcutaneous insulin infusion (CSII), time spent outside the glucose target was significantly different when comparing CGM without alarms and SMBG $(-1.9 \mathrm{~h} /$ day; $95 \% \mathrm{CI}-3.8$ to $0.0 ; \mathrm{P}=0.0461)$ and when comparing CGM with alarms and SMBG $(-2.4 \mathrm{~h} / \mathrm{day} ; 95 \%$ $\mathrm{CI}-4.1$ to $-0.5 ; \mathrm{P}=0.0134)$. There was no difference in A1c reduction from baseline in the three groups, with the average difference of around $3 \mathrm{mmol} / \mathrm{mol}(0.1 \%)$; however, the proportion of participants with a reduction of $\geq 6 \mathrm{mmol} /$ mol ( $\geq 0.5 \%$ ) was nonsignificantly higher in the continuous glucose monitoring without alarms $(27 \%)$ and continuous glucose monitoring with alarms groups $(25 \%)$ than in the self-monitoring of blood glucose group (10.6\%).

\section{Conclusions}

The use of CGM reduces time spent outside glucose targets compared with SMBG, especially among users of insulin pumps and in the hypoglycemic range.

\section{Comment}

A major problem of this study (4) is the fact that after 3 months of CGM use, the A1c remained above $8 \%$ in all groups and did not decrease for more than $0.1 \%$ from baseline, despite the fact that most participants were using CSII. The A1c decrease in CSII users was more pronounced, but not close to similar previous studies (5). This may indicate that participants in both CGM groups did not use the glucose information provided by CGM to the usual expected benefit, particularly as both CGM groups wore sensors for $>80 \%$ of the time. The fact that participants did not obtain specific algorithms instructing on the use of CGM information was not likely to influence the outcome $(5,6)$.

\section{Effect of lipohypertrophy on accuracy of continuous glucose monitoring in patients with type 1 diabetes}

DeSalvo DJ ${ }^{1}$, Maahs DM ${ }^{2}$, Messer $L^{2}$, Wadwa $R P^{2}$, Payne $S^{1}$, Ly $T T^{1,3}$, Buckingham $B A^{1}$

${ }^{1}$ Division of Pediatric Endocrinology and Diabetes, Department of Pediatrics, Stanford University School of Medicine, Stanford, CA; ${ }^{2}$ Barbara Davis Center for Child- hood Diabetes, University of Colorado, Aurora, CO; ${ }^{3}$ School of Paediatrics and Child Health, The University of Western Australia, Perth, Australia

Diabetes Care 2015. [Epub ahead of print] DOI 10.2337/dc151267

Aims

Long-term delivery of insulin in the same location induces fibrous lipohypertrophy, often causing slower, unpredictable insulin absorption. The effect on CGM sensor performance when inserted in sites with lipohypertrophy is unknown. The accuracy of sensors used simultaneously in lipohypertrophied and normal subcutaneous tissue was compared in this study.

\section{Methods}

Participants with T1D and lipohypertrophy of $>3 \mathrm{~cm}$ in diameter wore two Dexcom G4 Platinum sensors simultaneously for 2 consecutive weeks: one in lipohypertrophied tissue and the second in normal tissue. Blood glucose (BG) concentration measured with Bayer CONTOUR NEXT meters served as reference. The same procedure was then repeated on each subject with new sensors. Data from the first 7 days of sensor life were used in the analysis. Absolute relative difference (ARD) defined as the percent error between sensor and matched BG values was used and compared with Mann-Whitney U test.

\section{Results}

Twenty-nine subjects (48\% men, age $29.6 \pm 8.9$ years, duration of T1D $17.3 \pm 9.1$ years, A1c $7.5 \pm 0.8 \%$ $(58 \pm 8.7 \mathrm{mmol} / \mathrm{mol})$ enrolled in the study. The average diameter of lipohypertrophy was $8.1 \pm 3.5 \mathrm{~cm}$. There were 89,853 sensor glucose values between 40 and $400 \mathrm{mg} / \mathrm{dL}$ (range of sensor) with 1,547 corresponding BG readings. The median ARD for sensors in lipohypertrophied tissue was $10.0 \%(4.3,17.2)$ versus $11.0 \%(4.9,19.3)$ in normal tissue $(\mathrm{P}<0.001)$. Mean absolute difference (MAD) was not different for sensors in lipohypertrophied tissue as compared to sensors in normal tissue $(\mathrm{P}=0.14)$ for $\mathrm{BG} \leq 70 \mathrm{mg} / \mathrm{dL}$ or $\geq 250 \mathrm{mg} / \mathrm{dL}(\mathrm{P}=0.44)$. Proportion of all sensor values that were within $\pm 20 \%$ of reference meter value for BG $>80 \mathrm{mg} /$ $\mathrm{dL}$ was significantly higher for sensors in lipohypertrophied tissue as compared to sensors in normal tissue $(\mathrm{P}<0.003)$.

\section{Conclusions}

CGM sensors inserted in lipohypertrophied tissue demonstrated equal or somewhat superior accuracy across all glucose ranges as compared to sensors inserted in normal tissue.

\section{Comment}

These data (7) are likely surprising to many clinicians, particularly as the lipohypertrophied tissue is considered to be fibrous and relatively avascular. Indeed, the data suggest that the flow of interstitial fluid is not adversely affected inside the lipohypertrophied tissue. This observation has important direct clinical implications as 
lipohypertrophied tissue is commonly used for CGM sensor insertion sites. Further longer-term studies are needed to evaluate the potential risks of sensor use in areas of lipohypertrophy.

\section{Association between blood glucose variability and coronary plaque instability in patients with acute coronary syndromes}

Okada $K^{1}$, Hibi $K^{1}$, Gohbara $M^{1}$, Kataoka $S^{1}$, Takano $K^{1}$, Akiyama $E^{l}$, Matsuzawa $Y^{l}$, Saka $K^{1}$, Maejima $N^{l}$, Endo $M^{1}$, Iwahashi $N^{1}$, Tsukahara $K^{1}$, Kosuge $M^{1}$, Ebina $T^{1}$, Fitzgerald $P^{2}$, Honda $Y^{2}$, Umemura $S^{3}$, Kimura $K^{1}$

${ }^{1}$ Division of Cardiology, Yokohama City University Medical Center, Yokohama, Japan; ${ }^{2}$ Division of Cardiovascular Medicine, Stanford University Medical Center, Stanford, CA; ${ }^{3}$ Department of Medical Science and Cardiorenal Medicine, Yokohama City University Graduate School of Medicine, Yokohama, Japan

Cardiovasc Diabetol 2015; 14: 111

\section{Aims}

Blood glucose variability is more strongly associated with atherogenic factors such as oxidative stress, endothelial dysfunction, and inflammation compared to average hyperglycemia represented as A1c or FPG. The aim of this study was to investigate the association between blood glucose variability as measured by CGM and coronary tissue characteristics in patients with acute coronary syndromes (ACS).

\section{Methods}

ACS patients who underwent both percutaneous coronary intervention (PCI) with integrated backscatter (IB) intravascular ultrasound (IVUS) guidance in the culprit vessel and CGM measurement were eligible for enrollment into this prospective observational study. T2D was established according to the ADA criteria, and participants received no antidiabetic medications during the CGM measurements (iPro2, Medtronic). Standardized meals were provided. Blood glucose values were checked at least four times per day with a finger-stick test. Intravascular ultrasound analysis was performed with a validated quantitative IVUS analysis system (VISIATLAS, Terumo, Tokyo, Japan) by an experienced investigator, blinded to clinical information.

\section{Results}

A total of 76 consecutive patients with ACS who met the inclusion and exclusion criteria and underwent both IB-IVUS and CGM were enrolled, and data of 57 patients were analyzed (age $65 \pm 12$ years, $79 \%$ male, $49 \%$ had T2D). MAGE values were significantly correlated with maximum blood glucose values $(\mathrm{r}=0.88, \mathrm{p}<0.0001)$ and mean blood glucose values $(\mathrm{r}=0.55, \mathrm{p}<0.0001)$. A1c and FPG were positively correlated with maximum blood glucose, minimum blood glucose, mean blood glucose, and MAGE values. Urinary oxidative stress marker L-FABP values were significantly correlated with MAGE values $(r=0.37, p=0.008)$. MAGE values were positively correlated with plaque volumes, percent plaque volumes and remodeling index $(\mathrm{r}=0.27, \mathrm{p}=0.046)$, and FPG values were correlated with remodeling index $(\mathrm{r}=0.33, \mathrm{p}=0.013)$. Patients with significant hyperglycemia ( $\geq 200 \mathrm{mg} / \mathrm{dL})$ or significant hypoglycemia $(<60 \mathrm{mg} / \mathrm{dL}$ ) tended to have greater plaque burden compared to those without. Contrary to conventional glucose indicators (A1c, FPG, HOMA-IR), MAGE values were positively correlated with percent lipid volumes $(\% \mathrm{LV})$ and negatively with percent fibrous volumes $(\% \mathrm{FV})$, also in multiple regression analysis.

\section{Conclusions}

Higher blood glucose variability (MAGE) as measured by CGM was independently and more strongly associated with increased lipid and decreased fibrous contents, with larger plaque burden, and higher remodeling index in the culprit vessel of ACS patients as compared to conventional glucose indicators (A1c, FPG, HOMA-IR). Prospective, randomized controlled trials are needed to evaluate clinical implications of these observations and define treatment targets.

\section{Comment}

These data (8) add to the growing evidence that glucose variability independently induces oxidative stress and tissue damage. The assessment of blood glucose variability using CGM may contribute to better prediction of vulnerable plaques, and may become a new therapeutic target for the prevention of ACS in patients with coronary artery disease.

\section{Effect of daily glucose fluctuation on coronary plaque vulnerability in patients pre-treated with lipid-lowering therapy: a prospective observational study}

Kuroda $M^{l}$, Shinke $T^{l}$, Sakaguchi $K^{2}$, Otake $H^{l}$, Takaya $T^{l}$, Hirota $Y^{2}$, Sugiyama $D^{3}$, Nakagawa $M^{1}$, Hariki $H^{1}$, Inoue $T^{l}$, Osue $T^{1}$, Taniguchi $Y^{1}$, Iwasaki $M^{l}$, Nishio $R^{1}$, Kinutani $H^{1}$, Konishi $A^{1}$, Hiranuma $N^{1}$, Takahashi $H^{1}$, Terashita $D^{1}$, Hirata $K^{1}$

${ }^{1}$ Division of Cardiovascular Medicine, Department of Internal Medicine, Kobe University Graduate School of Medicine, Hyogo, Japan; ${ }^{2}$ Division of Diabetes and Metabolism, Department of Internal Medicine, Kobe University Graduate School of Medicine, Hyogo, Japan; ${ }^{3}$ Department of Preventive Medicine and Public Health, School of Medicine, Keio University, Tokyo, Japan

JACC Cardiovasc Interv 2015; 8: 800-11

\section{Aims}

Glucose variability contributes to the development of coronary artery disease (CAD) in addition to dyslipidemia, where the reduction of risk of CAD by statins has been reported to be only $30 \%$. This study investigated the effect of daily glucose fluctuation on coronary plaque properties in patients on stable lipid-lowering therapy.

\section{Methods}

Seventy consecutive patients with CAD between 20 and 80 years of age who were referred for percutaneous coronary 
intervention and whose low-density lipoprotein (LDL) cholesterol level was $<120 \mathrm{mg} / \mathrm{dL}$ under statin treatment or $<100 \mathrm{mg} / \mathrm{dL}$ without statins were enrolled into this prospective study; 23 were formerly diagnosed as having type 2 DM. A $75 \mathrm{~g}$ OGTT was performed in all patients, and levels of PG and insulin were evaluated just before and $30,60,90$, and $120 \mathrm{~min}$ after the oral glucose load. Daily glucose fluctuation was measured during 3 days (CGM System iPro2; Medtronic, Northridge, California) and the mean amplitude of glycemic excursion (MAGE) calculated. The plaque properties in the culprit and nonculprit lesions were assessed by virtual histology intravascular ultrasound (VH-IVUS examination; Eagle Eye Platinum 3.5F 20-MHz, Volcano Corp., Rancho Cordova, California), and the volume percentage of necrotic core within the plaque $(\% \mathrm{NC})$ and the presence of thin-cap fibroatheroma were evaluated.

\section{Results}

In addition to 23 patients with previously diagnosed T2D, OGTT testing detected 17 with newly diagnosed T2D and 20 with IGT. Mean A1c in 40 patients with T2D was $6.8 \pm 1.0 \%$. Mean LDL cholesterol concentration in all participants was $87.8 \pm 18.7 \mathrm{mg} / \mathrm{dL}$ and mean RR $121.6 \pm 12.1$ over $62.6 \pm 7.8 \mathrm{mmHg}$. In total, 165 lesions were evaluated in 70 patients. $\% \mathrm{NC}$ was well correlated with MAGE $(\mathrm{r}=0.490, \mathrm{p}<0.001)$. \% NC was significantly correlated with FPG, 2h-OGTT PG, Alc, mean BG by CGM, time in hyperglycemia, and MAGE. A linear mixed effect model showed that MAGE had the strongest effect on \% NC (coefficient $\beta=0.080 \pm 0.020$ [standard error], $\mathrm{p}<0.001$ ). The generalized linear mixed effect model adjusted with confounders revealed that MAGE was the only independent predictor of the presence of thin-cap fibroatheroma (odds ratio: $1.037 ; 95 \%$ confidence interval: 1.010 to 1.065 ; $\mathrm{p}=0.007)$. In multivariate analysis MAGE had a stronger positive correlation with $\% \mathrm{NC}$ than with the duration of T2D, and was independently associated with the formation of $\mathrm{NC}$ in non-T2D patients.

\section{Conclusions}

Daily glucose fluctuations may represent an independent additional risk for coronary plaque vulnerability in patients with CAD pretreated with lipid-lowering therapy. Routine detection of glucose fluctuation with CGM and appropriate management, apart from the control of dyslipidemia, may be warranted. Further investigations evaluating the effectiveness of early detection and control of glucose fluctuation with concomitant statin therapy for CAD patients are needed.

\section{Comment}

This study (9) strengthens the previous evidence as all included patients had LDL cholesterol within recommended limits. Additionally, MAGE was associated with plaque vulnerability also in patients without T2D, suggesting an independent detrimental effect of glucose variability.

\section{Glycemic variability determined by continuous glucose monitoring system predicts left ventricular remodeling in patients with a first ST-segment elevation myocardial infarction}

Gohbara $M^{l}$, Iwahashi $N^{1}$, Kataoka $S^{l}$, Hayakawa $Y^{2}$, Sakamaki $K^{3}$, Akiyama $E^{1}$, Maejima $N^{1}$, Tsukahara $K^{1}$, Hibi $K^{1}$, Kosuge $M^{1}$, Ebina $T^{1}$, Umemura S, Kimura $K^{1}$

${ }^{1}$ Division of Cardiology, Yokohama City University Medical Center, Yokohama, Japan; ${ }^{2}$ Division of Radiology (Y.H.), Yokohama City University Medical Center, Yokohama, Japan; ${ }^{3}$ Department of Biostatistics and Epidemiology, Department of Medical Science and Cardiorenal Medicine, Yokohama City University Graduate School of Medicine, Yokohama, Japan

Circ J 2015; 79: 1092-99

\section{Aims}

Some patients with ST-segment elevation myocardial infarction (STEMI) have either large infarct or left ventricular remodeling (LVR), both of which lead to a poor outcome accompanied by heart failure even after successful early coronary artery reperfusion. In the present study, the clinical impact of glucose variability (GV) evaluated by CGM on infarct size and LVR as assessed by cardiac magnetic resonance (CMR) in patients at 7 months after the first STEMI was prospectively investigated.

\section{Methods}

Initially, 194 consecutive patients with a first STEMI reperfused within $12 \mathrm{~h}$ of symptom onset were screened for inclusion to the study. Patients using medication for diabetes or hyperglycemia were excluded. All patients underwent an early CMR on day $9 \pm 4$ as a baseline using a 1.5-T CMR system with an 8-element phased-array cardiac coil (MAGNETOM Avanto; Siemens Medical Solutions, Inc, Erlangen, Germany), and a late CMR at $7 \pm 1$ months according to the same protocol. All CMR images were interpreted independently by two radiologists, blinded to the angiographic and clinical data, using Q-MASS MR 7.5 (Medis, Leiden, the Netherlands). A CGM (iPro2; Medtronic, Minneapolis, MN) was inserted when in a stable phase after revascularization for at least 24 consecutive hours. MAGE was calculated by measuring the arithmetic mean of the differences between consecutive peaks and nadirs if the differences were greater than 1 standard deviation (SD) of the mean glucose value. A standard $75 \mathrm{~g}$ OGTT was performed in stable condition.

\section{Results}

There was no significant difference between group L (lower 2 tertiles of MAGE) and group $\mathrm{H}$ (upper tertile of MAGE) in regard to A1c levels on admission or at 7 months (average A1c between 5.8 and 6.0\%). LVR was defined as an absolute increase in left ventricular end-diastolic volume index of $\geq 20 \%$. LVR more frequently occurred in group $\mathrm{H}$ than in group $\mathrm{L}(56 \%$ vs. $11 \%, \mathrm{P}<0.001)$. Univariate analysis demonstrated the higher MAGE group was a strong predictor of LVR $(\mathrm{P}<0.001)$. In the multivariate logistic regression analysis by forced inclusion model, the higher MAGE group was an independent predictor of LVR (odds ratio: 13.999; 
95\% CI: 3.059-64.056; $\mathrm{P}=0.00$ ), independently of A1c on admission and glucose on admission.

\section{Conclusions}

MAGE early after the onset of STEMI identified patients with LVR in the chronic phase. Evaluation of MAGE by CGM enables effective identification of patients requiring more aggressive treatment against LVR, possibly also by strategies for reducing GV.

\section{Comment}

This extremely interesting prospective observational study (10) adds to an increasing amount of data demonstrating that glucose variability in patients without a diagnosis of T2D and independently of A1c or other measures of mean glycemia conveys a seriously increased risk for poorer outcomes of cardiovascular diseases. All three recent observational studies described above (8-10) and several others confirm this observation from different angles. An even more recent study correlated MAGE to rapid progression (RP) of nonculprit lesion in acute coronary syndrome (RP was defined as $\geq 10 \%$ diameter reduction in a preexisting stenosis $\geq 50 \%$; $\geq 30 \%$ diameter reduction in a stenosis $<50 \%$; development of a new stenosis $\geq 30 \%$ in a previously normal segment; or progression of any stenosis to total occlusion); on multiple logistic regression analysis, MAGE was an independent predictor of RP (odds ratio, 1.06 per $1 \mathrm{mg} / \mathrm{dL} ; \mathrm{P}<0.01$ ) (11). It is therefore reasonable to expect randomized interventional trials that will attempt minimizing $\mathrm{GV}$ before and after acute coronary events.

\section{Correlation of continuous glucose monitoring profiles with pregnancy outcomes in nondiabetic women}

Sung $J F^{1}$, Kogut $E A^{2}$, Lee $H C^{3}$, Mannan $J L^{4}$, Navabi $K^{5}$, Taslimi $M M^{6}$, El-Sayed $Y Y^{6}$

${ }^{1}$ Division of Maternal-Fetal Medicine, Department of $\mathrm{Ob}$ stetrics and Gynecology, University of Colorado Denver, Aurora, CO; ${ }^{2}$ Department of Obstetrics and Gynecology, Stanford University, Stanford, CA; ${ }^{3}$ Division of Neonatal and Developmental Medicine, Department of Pediatrics, Stanford University, Stanford, CA; ${ }^{4}$ Department of $\mathrm{Ob}$ stetrics and Gynecology, Santa Clara Valley Medical Center, San Jose, CA; ${ }^{5}$ Division of Endocrinology and Metabolism, Department of Internal Medicine, University of New Mexico, Albuquerque, NM; ${ }^{6}$ Division of MaternalFetal Medicine, Department of Obstetrics and Gynecology, Stanford University, Stanford, CA

Amer J Perinatol 2015; 32: 461-68

\section{Aims}

To investigate if hyperglycemic excursions documented by CGM at various thresholds correlate with birth weight percentile and other pregnancy outcomes, and compare this correlation to the correlations with a single glucose value from a 1-hour glucose challenge test (GCT).

\section{Methods}

A total of 55 pregnant women without preexisting diabetes participated in this prospective observational study, wearing a CGM device for up to 7 days, between 24 and 28 weeks of gestation. The area under the curve (AUC) of hyperglycemic excursions above various thresholds (110, 120, 130, 140, and $180 \mathrm{mg} / \mathrm{dL}$ ) was calculated and, along with results from a standard $50 \mathrm{~g}$ GCT, correlated with the primary outcome of birth weight percentile, and secondary outcomes of unplanned operative delivery, pregnancy complications, delivery complications, fetal complications, and neonatal complications.

\section{Results}

A consistent significant correlation was seen between most AUC thresholds and birth weight percentile $(r=0.29, p<0.05$ for AUC 110, 120, 130, and $140 \mathrm{mg} / \mathrm{dL} ; r=0.25, p=0.07$ for AUC $180 \mathrm{mg} / \mathrm{dL})$. These correlations were stronger than that of 1-hour oral GCT, which did not reach statistical significance $(r=-0.02, p=0.88)$. There was no correlation between AUC values and secondary outcomes.

\section{Conclusions}

Hyperglycemic excursions detected by CGM were significantly correlated to birth weight percentile in nondiabetic pregnancy, stronger than blood glucose values obtained at 1 hour after a $50 \mathrm{~g}$ oral GCT.

\section{Comment}

This important observational study (12) adds to the existing knowledge on CGM data in pregnancies complicated by various types of diabetes. Interestingly, even moderate elevations of glucose concentration in midpregnancy associate with higher birth weight. A recent analysis of data from two studies in pregnant women with diabetes demonstrated that distinct patterns of hyperglycemia in the second and third trimester cause increased birth weight (13). Furthermore, hyperglycemia is associated with increased fetal heart rate in a smaller observational study (14), possibly adding to the damage of the fetal heart muscle. CGM appears to be more sensitive than conventional testing of hyperglycemia and may become a routine test in mid-pregnancy, replacing current glucose challenge tests.

\section{Routine use of continuous glucose monitoring in 10,501 people with diabetes mellitus}

Battelino $T^{1,2}$, Liabat $S^{3}$, Veeze $\mathrm{HJ}^{4}$, Castaneda $\mathrm{J}^{5}$, Arrieta $A^{5}$, Cohen $O^{6}$

${ }^{1}$ University Medical Centre Ljubljana, Ljubljana, Slovenia; ${ }^{2}$ Faculty of Medicine, University of Ljubljana, Ljubljana, Slovenia; ${ }^{3}$ Medtronic International Trading Sarl, Tolochenaz, Switzerland; ${ }^{4}$ Diabeter, Centre for Pediatric and Adolescent Diabetes Care and Research, Rotterdam, The Netherlands; ${ }^{5}$ Medtronic Bakken Research Center, Maastricht, The Netherlands; ${ }^{6}$ Chaim Sheba Medical Centre, Ramat Gan, Israel 
Diabet Med June 4, 2015. [Epub ahead of print] DOI 10.1111/ dme.12825

\section{Aims}

Pump therapy linked with CGM (sensor-augmented pump therapy-SAP) is associated with a significant increase in the time spent within normal glycemic range, and a decrease in the number of hypoglycemic events and duration of hypoglycemia. The generalizability of results obtained with CGM in controlled clinical trials to the routine day-to-day use remains to be established. The aim of the present study was to analyze glycemic control from self-monitoring of blood glucose (SMBG) data in relation to CGM use in people with diabetes included in the CareLink database (Medtronic, Tolochenaz, Swiss), and to identify factors associated with prolonged CGM use.

\section{Methods}

CareLink data collected from 21,196 people with diabetes in Western Europe, Israel, and Canada were analyzed; 10,695 had $<6$ months of data and were excluded. All individuals included in the analysis had at least 6 months' downloaded data and at least one sensor reading in CareLink. Sensor users were defined as patients with at least 15 days of sensor usage within any 6-month period; all others were designated "nonusers." Measures of glycemic variability were derived from SMBG, rather than sensor glucose values, to obtain greater consistency in the number of blood glucose measurements between groups. SMBG values were also used to estimate A1c levels.

\section{Results}

Of 10,501 patients included in the analysis, 7,916 had at least 15 days of sensor use within a 6-month period, and 2,585 were nonusers. Compared with patients in the lowest sensor usage group and nonusers, the highest glucose sensor usage group had significantly $(\mathrm{P}<0.0001)$ lower mean blood glucose and blood glucose SD (the mean decrease in blood glucose in the highest sensor usage group, compared with nonusers, was $0.26 \mathrm{mmol} / \mathrm{L}$, corresponding to a decrease in A1c concentration of $0.2 \%$ ), were more likely to achieve a mean blood glucose concentration $<8.6 \mathrm{mmol} / \mathrm{L}[155 \mathrm{mg} /$ $\mathrm{dL}]$ ), (odds ratio $1.5,95 \% \mathrm{CI} 1.3-1.7 ; \mathrm{P}<0.0001$ ), and had $50 \%$ fewer hypoglycemic (blood glucose concentration $<2.8 \mathrm{mmol} / \mathrm{L}$ [50 mg/dL]) episodes. The mean proportion of blood glucose values in the range $3.9-10.0 \mathrm{mmol} / \mathrm{L}$ [70$180 \mathrm{mg} / \mathrm{dL}]$ increased significantly with sensor use $(\mathrm{P}<0.0001$ for the highest users compared with all other users). Patients using the sensor least during the first month were approximately twice as likely to discontinue sensor use than those in the highest usage group. During the first month and over the entire treatment period, patients in the lowest sensor usage group were significantly $(\mathrm{P}<0.001)$ more likely to discontinue SAP therapy compared to those in higher usage groups.

\section{Conclusions}

The use of CGM in this analysis from a large patient database was significantly associated with reductions in hypoglycemia and slightly improved metabolic control in patients on insulin pump therapy in everyday life. Sensor use during the first month was strongly associated with long-term adherence.

\section{Comment}

Lately, "big data" analyses from electronic patients' registries gained considerable attention from health-care practitioners and health-insurance systems alike. With all inherent limitations related to the rather inconsistent data input (mostly patient-driven voluntary uploads of data), these analyses provide a broad inside into the routine day-to-day behavior patterns related to the use of a particular health technology, and therefore also to its real-life acceptance and efficacy. The analysis of this large European database (15) clearly demonstrated that CGM linked to an insulin pump has passed this realitycheck quite successfully with both major benefits observed in several randomized controlled trials, namely the reduction of hypoglycemia with a concomitant improvement in glycemic control, confirmed with statistical significance and clinical relevance also in day-to-day routines. Similarly, an inside-the-company analysis of a large U.S. anonymous database on the use of the automatic Threshold Suspend (TS) feature of the MiniMed 530G system (Medtronic MiniMed, Inc., Northridge, CA) used data from 20,973 patients who enabled the TS feature at their discretion and uploaded pump and sensor data to CareLink (Medtronic MiniMed, Inc.) (16). Comparisons between 758,382 patient-days wherein the TS feature was enabled at any time and 166,791 patientdays in which it was not enabled were made: the former group had $69 \%$ fewer $\mathrm{SG}$ values $<50 \mathrm{mg} / \mathrm{dL}$ compared to the later $(0.64 \%$ vs. $2.09 \%$, respectively; $\mathrm{P}<0.001)$, with the reduction in hypoglycemia seen on TS-enabled days being more pronounced during nighttime. SG data from full-time users of the TS feature demonstrated a $62 \%$ reduction in values $<50 \mathrm{mg} / \mathrm{dL}$, an $8.2 \%$ increase in values $>180 \mathrm{mg} / \mathrm{dL}$, a $7.4 \%$ increase in values $>240 \mathrm{mg} /$ $\mathrm{dL}$, and a $5.6 \%$ reduction in values $>300 \mathrm{mg} / \mathrm{dL}$ compared with data from nonusers $(\mathrm{P}<0.001$ for each). The median SG value at the start of $2 \mathrm{~h}$ suspensions was 60 (interquartile range [IQR], 57-66) $\mathrm{mg} / \mathrm{dL}$, immediately after was 87 (IQR, 63-123) $\mathrm{mg} / \mathrm{dL}$, and $4 \mathrm{~h}$ later was 164 (IQR, 117-220) mg/dL. The TS feature, when enabled consistently, reduced hypoglycemic exposure with a moderate increase in subsequent hyperglycemia between 180 and $300 \mathrm{mg} / \mathrm{dL}$. Large centers also published their own long-term registries-based observational data demonstrating overall improvement of metabolic control related to the use of diabetes technology (17). These sizable observational data are likely of interest also to various insurance systems as they demonstrate real-life outcomes with relevant long-term financial implications.

\section{Accuracy of two continuous glucose monitoring systems: a head-to-head comparison under clinical research centre and daily life conditions}

Kropff $\mathrm{J}^{1}$, Bruttomesso $\mathrm{D}^{2}$, Doll $\mathrm{W}^{3}$, Farret $A^{4}$, Galasso $S^{2}$, Luijf $Y^{1}$, Mader $\mathrm{JK}^{3}$, Place $\mathrm{J}^{4}$, Boscari $F^{2}$, Pieber $T R^{3}$, Renard $E^{4}$, DeVries $\mathrm{JH}^{1}$ 
${ }^{I}$ Department of Internal Medicine, Academic Medical Center, University of Amsterdam, Amsterdam, the Netherlands; ${ }^{2}$ Department of Clinical and Experimental Medicine, University of Padova, Padova, Italy; ${ }^{3}$ Department of Internal Medicine, Medical University Graz, Graz, Austria; ${ }^{4}$ Department of Endocrinology, Diabetes, Nutrition and INSERM Clinical Investigation Centre, Montpellier University Hospital, Montpellier, France

Diabetes Obesity and Metabolism 2015; 17: 343-49

\section{Aims}

This study aimed to assess and compare the accuracy of two commercially available CGM devices in a way that includes both a standardized assessment within a CRC and usage during everyday life.

\section{Methods}

This study was funded by Dexcom, San Diego, and was performed in 2013. Twenty-four adult patients with T1D for at least 6 months (body mass index $<35 \mathrm{~kg} / \mathrm{m}^{2}$ and A1c level $<10 \%$ [86 mmol/mol]) wore two sensors simultaneously for 6 days: the Dexcom G4 platinum (DG4P; Dexcom, San Diego, $\mathrm{CA}$ ) and the Medtronic Paradigm Veo Enlite system (ENL; Medtronic, Northridge, CA). The DG4P devices were obtained directly from Dexcom and the ENL devices through the local Medtronic affiliated company. Patients were asked to calibrate the CGM twice a day after the initial calibration against capillary blood finger-stick measurements using an Accu-Chek Aviva series blood glucose meter (Roche Diagnostics, Mannheim, Germany) with glucose strips from the same production lot, provided for the study. On day 3 from 8:00 till 14:00, venous blood sampling at the CRC was performed every $5 \mathrm{~min}$ for the first $15 \mathrm{~min}$ and every $15 \mathrm{~min}$ thereafter, with the exception of the time between 09:00 and 10:00 and from 11:00 to 12:00 h, when samples were taken every $10 \mathrm{~min}$ to register the glucose peak after breakfast or the glucose nadir, respectively. After bedside centrifuging, venous plasma was analyzed using the YSI 2300 STAT PLUS glucose and lactate analyzer (YSI, Yellow Springs, OH). Hypoglycemia (3.0-3.9 mmol/L [54-70 $\mathrm{mg} / \mathrm{dL}]$ ) was induced with an additional bolus. The rest of the 6 days was individual routine life.

\section{Results}

The 24 patients ( $67 \%$ male) were $40 \pm 11.8$ years old, had T1D for $23.5 \pm 13.5 \mathrm{y}$, and A1c $8.0 \pm 3.0 \%(64 \pm 9 \mathrm{mmol} / \mathrm{mol})$. Overall sensor accuracy at the CRC phase expressed as MARD \pm SD was $13.6 \pm 11.0 \%$ for the DG4P $(n=532)$ and $16.6 \pm 13.5 \%$ for the ENL $(\mathrm{n}=530)$; it was $17.6 \pm 12.2 \%$ $(n=117)$ for the DG4P and $24.6 \pm 18.8 \%(n=117)$ for the ENL in the hypoglycemic range $(\leq 3.9 \mathrm{mmol} / \mathrm{L}[70 \mathrm{mg} / \mathrm{dL}])$, and $6.2 \pm 5.0 \%(\mathrm{n}=28)$ for the DG4P and $17.1 \pm 8.8 \%(\mathrm{n}=28)$ for the ENL in the hyperglycemic range $(\geq 10 \mathrm{mmol} / \mathrm{L}[180 \mathrm{mg} /$ $\mathrm{dL}]$ ); all differences were statistically significant at $\mathrm{p}<0.001$. Overall sensor accuracy at the real-life phase expressed as MARD \pm SD was $12.2 \pm 12.0 \%$ for the DG4P $(\mathrm{n}=987)$ and $19.9 \pm 20.5 \%$ for the ENL $(n=839) ; 21.2 \pm 21.8 \%(n=56)$ for the DG4P and $36.5 \pm 42.6 \%(\mathrm{n}=47)$ for the ENL in the hypoglycemic range $(\leq 3.9 \mathrm{mmol} / \mathrm{L}[70 \mathrm{mg} / \mathrm{dL}])$, and $11.6 \pm 10.6 \%$ $(n=327)$ for the DG4P and $18.0 \pm 16.7 \%(n=287)$ for the ENL in the hyperglycemic range $(\geq 10 \mathrm{mmol} / \mathrm{L}[180 \mathrm{mg} / \mathrm{dL}])$; all differences were statistically significant at $p<0.001$. The DG4P had significantly better average accuracy on each separate day and a significantly higher percentage of values in the Clarke Error Grid (CEG) zone A (83.0 vs. $64.6 \%$; $p<0.0001)$.

\section{Conclusions}

The DG4P is significantly more accurate than the ENL CGM system. The difference in accuracy between the two systems did not translate into a difference in clinically more relevant outcomes, such as sensitivity for hypoglycemia and false-positive hypoglycemia alarm rate; however, this study was not powered to detect those.

\section{Comment}

This study was designed and performed in an academic setting, however it was funded by Dexcom (18). An important bias was introduced as the DG4P devices were obtained directly from Dexcom and the ENL devices through the local Medtronic affiliated company. Sensors, provided directly from a company for a sponsored study investigating their accuracy, may not be the same as "off-the-shelf" sensors purchased from a provider. However, the results related to ENL (Medtronic) systems are likely not biased and represent a view on dayto-day reality. Better CGM accuracy is expected to result in better clinical outcomes, such as better patient acceptance with increased trust in the device. Therefore, CGM manufacturers are expected to analyze accuracy data coming from academia designed "real-life" studies and use them for further sensor developments.

\section{A clinical trial of the accuracy and treatment experience of the Dexcom G4 Sensor (Dexcom G4 System) and Enlite Sensor (Guardian REAL-Time System) tested simultaneously in ambulatory patients with type 1 diabetes}

Matuleviciene $V^{1}$, Joseph $\mathrm{JI}^{2}$, Andelin $\mathrm{M}^{3}$, Hirsch $\mathrm{IB}^{4}$, Attvall $S^{1}$, Pivodic $A^{5}$, Dahlqvist $S^{3}$, Klonoff $D^{6}$, Haraldsson $B^{1}$, Lind $M^{1,3}$

${ }^{1}$ Institute of Medicine, University of Gothenburg, Gothenburg, Sweden; ${ }^{2}$ Department of Anesthesiology, Jefferson Medical College of Thomas Jefferson University, Philadelphia, PA, ${ }^{3}$ Department of Medicine, NU-Hospital Organization, Uddevalla, Sweden; ${ }^{4}$ University of Washington, Seattle, WA; ${ }^{5}$ Statistiska Konsultgruppen, Gothenburg, Sweden; ${ }^{6}$ Diabetes Research Institute, Mills-Peninsula Health Services, San Mateo, CA

\section{Diabetes Technol Ther 2014; 16: 759-67}

\section{Aims}

The purpose was to evaluate and compare the accuracy and patient treatment satisfaction of two commercial CGM systems: the Enlite (Medtronic MiniMed, Inc., Northridge, CA) and G4 PLATINUM (Dexcom, San Diego, CA).

\section{Methods}

The study was funded by public grants without any industry sponsorship. Patients with T1D who were between 18 
and 75 years old, not pregnant, without cognitive dysfunction or other disease making CGM use difficult, who did not use paracetamol, or a CGM sensor in recent weeks were invited. All participants used both CGM systems simultaneously unmasked for 4 to 6 days, were trained to use the HemoCue (Ängelholm, Sweden) glucose analyzer, and were advised to measure capillary glucose values 6 to 10 times per day. Each patient was admitted twice to the CRC to obtain seven venous blood samples with an interval of at least 15 min on days 1-3 and 4-6. The HemoCue analyzer was used to measure both venous and capillary blood samples. Patient experience was evaluated with 13 predefined questions on a visual analogue scale (VAS). The primary end point was the difference in mean absolute relative difference (MARD) between the two sensors, using capillary glucose values as the reference.

\section{Results}

From 46 enrolled subjects 38 met the predefined intentionto-treat criteria for the analysis (mean age 50.0 years, 66\% male, mean diabetes duration 22.9 years, mean A1c level $58.9 \mathrm{mmol} / \mathrm{mol}$ [7.5\%], 10 patients used CSII). The primary end point analysis showed MARD for the Dexcom G4 was significantly lower than for the Enlite sensor (13.9\% vs. $17.8 \% ; \mathrm{P}<0.0001, \mathrm{n}=1,012$ measurements). The corresponding MARDs for days $1-3(\mathrm{n}=545)$ were $15.0 \%$ vs. $19.4 \%,(\mathrm{P}=0.0027)$, and days $4-6(\mathrm{n}=467) 13.6 \%$ vs. $15.9 \%$, $(\mathrm{P}=0.026)$. For glucose levels $<4.0 \mathrm{mmol} / \mathrm{L}(\mathrm{n}=80)$ the MARD was $20.0 \%$ vs. $34.7 \%(\mathrm{P}=0.0041)$, for glucose levels $4-10 \mathrm{mmol} / \mathrm{L}(\mathrm{n}=668) 14.1 \%$ vs. $17.3 \%(\mathrm{P}=0.0008)$, and for glucose levels $>14 \mathrm{mmol} / \mathrm{L}(\mathrm{n}=70) 12.1 \%$ vs. $13.9 \%$ $(\mathrm{P}=0.24$ - nonsignificant $)$. MAD and the absolute correlation coefficient as measures for accuracy showed a similar pattern, with generally greater accuracy for the Dexcom G4. Patients rated the Dexcom G4 significantly more favorably than the Enlite system in 12 out of 13 user experience questions. Average rates of patient-reported signal disturbances were significantly lower for the Dexcom G4 than the Enlite $(0.7$ vs. $4.1, \mathrm{P}<0.0001)$. Local reactions after sensors' removal were rare and did not differ significantly between sensors.

\section{Conclusions}

The Dexcom G4 sensor showed greater accuracy than the Enlite sensor over the entire study period as well as in the first and the second period of analysis. The Dexcom G4 also showed greater accuracy in the hypoglycemic and euglycemic ranges, whereas no significant difference was found at very high glucose levels ( $>14 \mathrm{mmol} / \mathrm{L}$ ). Patients rated treatment experience as more positive with the Dexcom G4.

\section{Comment}

This important independent study provides valuable data relevant for clinical use (19). As the amount of time using a CGM correlates with the treatment effects on A1c it is likely that a sensor perceived as more positive by patients may be associated with a better long-term adherence, particularly if the initial experience is positive (15). This is also the first study that clearly associates sensor accuracy and reliability with patient-reported experience. Interestingly, convenience may be more important to patients than sheer accuracy itself, providing that the accuracy is within clinical safety. No safety issues were reported in this study.

\section{The performance and usability of a factory- calibrated flash glucose monitoring system}

Bailey $T^{l}$, Bode $B W^{2}$, Christiansen $M P^{3}$, Klaff $\mathrm{LJ}^{4}$, Alva $\mathrm{S}^{5}$

${ }^{1}$ AMCR Institute, Escondido, CA; ${ }^{2}$ Atlanta Diabetes Associates, Atlanta, GA; ${ }^{3}$ Diablo Clinical Research, Walnut Creek, CA; ${ }^{4}$ Rainier Clinical Research Center, Renton, WA; ${ }^{5}$ Clinical Affairs, Abbott Diabetes Care, Alameda, CA

Diabetes Technol Ther July 14, 2015. [Epub ahead of print]; DOI 10.1089/dia.2014.0378

\section{Aims}

The aim of the study was to evaluate the performance and usability of the FreeStyle Libre Flash glucose monitoring system (Abbott Diabetes Care, Alameda, CA) for interstitial glucose results compared with capillary blood glucose results measured with the built-in BG meter, and with the venous blood measurements.

\section{Methods}

The study was conducted at four U.S. clinical sites. Study participants wore the sensor without any overbandage on the back of each upper arm (two sensors total) for up to 14 days. Three factory-calibrated sensor production lots were used. Three scheduled in-clinic visits during the 14-day sensor wear period were scheduled between Day 1 and 3, Day 4 and 9, and Day 10 and 14, where venous blood samples were collected every $15 \mathrm{~min}$ over an $8 \mathrm{~h}$ period for YSI analyzer (Yellow Springs Instrument, Yellow Springs, $\mathrm{OH}$ ) reference tests. At least eight capillary BG tests using the built-in meter were required on each day, both at home and in the clinic, always followed immediately by a successful sensor scan, masked to participants. Capillary BG tests coincided with venous YSI samples drawn during in-clinic visits. A linear mixed model was used to assess sensitivity and mean absolute relative difference (MARD) between insertion sites, with subject as a random effect and insertion site (left arm, right arm) and sensor lot as fixed effects.

\section{Results}

Seventy-two of 75 study participants were included in the evaluation (aged 46.4 \pm 15.1 years, BMI 28.3 \pm 5.3 , duration of diabetes $23.0 \pm 13.1$, mean A1c $7.8 \pm 1.2 \%$ ). In total, 13,195 BG and 12,172 YSI reference results were paired with sensor glucose results, with 28 pairs excluded because the reference glucose result was beyond the BG system's dynamic range (20-500 mg/dL), and 114 pairs excluded because the sensor result was beyond the system's dynamic range $(40-500 \mathrm{mg} /$ dL). A total of $86.7 \%$ and $85.5 \%$ of results were in Zone A of the Consensus and Clarke Error Grids, respectively; $99.7 \%$ and $99.0 \%$ of sensor results were in Zones A and B of the Consensus and Clarke Error Grids, respectively; and $86.2 \%$ 
and $82.8 \%$ of sensor results were within $-15 \mathrm{mg} / \mathrm{dL}$ or $-20 \%$ of $\mathrm{BG}$ reference and venous reference, respectively. The overall MARD for sensor results with capillary BG reference was $11.4 \%$. The overall MARD for sensors' results with capillary BG reference and with YSI reference in the clinic was $12.1 \%$ and $12 \%$, respectively. The mean lag time between the system sensor and YSI reference was 4.5-4.8 min.

Body mass index, age, type of diabetes, clinical site, insulin administration, or A1c did not affect sensor accuracy. No unexpected adverse device effects were reported during the study. One participant had a serious adverse event-severe hypoglycemia prior to sensor insertion. Skin issues assessed in 202 site exams of 72 study participants were rare: moderate to severe itching $0.5 \%$ of the time, moderate erythema $4.0 \%$ of the time, and $98.6 \%$ of the insertions had a pain rating of 2 .

\section{Conclusions}

The performance of the factory precalibrated FreeStyle Libre Flash glucose monitoring system demonstrated clinically acceptable accuracy and stability of accurate readings over 14 days of use, unaffected by subject characteristics.

\section{Comment}

The FreeStyle Libre is different from existing interstitial glucose monitoring technologies in that the sensor has wear time of up to 14 days without any finger-stick calibration by the patient. The present accuracy data (20) are comparable or better to the existing commercially available CGM technology. These characteristics, associated with reduced burden and pain, may support more frequent sensor use with improved glycemic outcomes also in patients inclined to poor adoption of persistent sensor use. At the same time, the device may considerably increase the amount of information on glucose concentrations in patients using only SMBG. Randomized controlled clinical trials are warranted.

\section{Long-term home study on nocturnal hypoglycemic alarms using a new fully implantable continuous glucose monitoring system in type 1 diabetes}

\author{
Wang $X^{1}$, Ioacara $S^{2,3}$, DeHennis $A^{l}$ \\ ${ }^{1}$ Senseonics Inc., Germantown, MD; " "Carol Davila" \\ University of Medicine and Pharmacy, Bucharest, Romania; \\ and '“Elias" Emergency University Hospital, Bucharest, \\ Romania \\ Diabetes Technol Ther July 15, 2015. [Epub ahead of print] \\ DOI 10.1089/dia.2014.0375
}

\section{Aims}

This study analyzed the overall nocturnal performance during home use of a long-term CGM with subcutaneous implantable wireless glucose sensor and a body-worn transmitter.

\section{Methods}

Twelve participants with T1D (age $37 \pm 8$ years; disease duration $11 \pm 6$ years) were implanted with an investigational continuous glucose sensor constructed of a fluorescent, boronic-acid-based glucose indicating polymer coated onto a miniaturized, polymer-encased optical detection system in the upper arm for up to 90 days. The external transmitter wirelessly communicates with and powers the implanted sensor and has Bluetooth capability for interfacing with a smartphone application. All subjects received full access to real-time glucose data and user programmable hypo- and hyperglycemic alarms. Subjects calibrated the sensors with a self-monitoring of blood glucose (SMBG) meter used for their routine diabetes management; these measurements were used for calculating the accuracy of the sensor. The nocturnal sensor attenuation (NSA) concept was tested and sensitivity/ specificity of the nocturnal hypoglycemic alarms were calculated.

\section{Results}

The implantable glucose sensor life span was $87 \pm 7$ days. The average MARD over the range of $40-400 \mathrm{mg} / \mathrm{dL}$ for the sensors in this home-use study was $12.3 \pm 0.7 \%$ using SMBG as the reference. The hypoglycemia alarms set at the glucose level $<70 \mathrm{mg} / \mathrm{dL}$ for at least $10 \mathrm{~min}$ were triggered in $13.6 \%$ of the nights. The implanted continuous glucose sensor showed a hypoglycemia detection sensitivity and specificity of $77 \%$ and $96 \%$, respectively. The NSA-associated high negative rate of change of at least $-4 \mathrm{mg} / \mathrm{dL} / \mathrm{min}$ was not encountered during night use of the system. No serious adverse events were reported.

\section{Conclusions}

This home-use study of a fully implantable, long-term continuous glucose sensor demonstrated comparable performance to existing CGM devices in nocturnal hypoglycemia detection in participants with T1D. The sensitivity and high specificity of the hypoglycemic alarm possibly shortened nighttime hypoglycemia.

\section{Comment}

The 90-day study with this Senseonics implantable sensor (21) complements data from a recent study where MARD for all sensors was $11.6 \pm 0.7 \%$, and Clarke Error Grid analysis showed $99 \%$ of paired data points in the combined A and B zones over a 28-day use (22). The data are so far limited to one center and should be reproduced in a larger, multicenter study. However, this long-term implantable sensor may represent the beginning of a new clinical era in CGM, which will be warmly welcomed by patients and HCPs alike.

\section{Conclusion}

This short overview of selected recent publications opens several threads of thought. A practical one, related to the established routine use of CGM that culminated in the review and meta-analysis (23) and the evidence-informed recommendations for treatment of T1D complicated by problematic hypoglycemia (24) is closest to our traditional understanding of diabetes management. Similarly, we keep getting reminded that most of our patients spend a majority of their time outside the recommended glycemic ranges (25). A wider 
availability, higher reimbursement, and better acceptance (26) of CGM systems could clearly help many patients, which is demonstrated also by the use of CGM in more challenging situations like fasting $(27,28)$ or sport $(29,30)$. Novel clinical implications of glucose variability in the spectrum of T2D seem particularly exciting, starting from increased glucose variability before the diagnosis of impaired glucose tolerance is established. Reputable journals from the field of cardiovascular medicine, perinatology, nephrology (31), and several other fields publish clinical research with evidence that CGM may be superior to established diagnostic procedures or may even represent a prerequisite for a novel therapeutic target: the glucose variability. Looking back on the year before (32) and comparing it to recent publications, routine CGM made several new decisive steps into broadly accepted clinical use. This routine use is complemented with clinical data on long-term implantable and also intravascular sensors, connecting our threads of thought to dreams (33).

\section{Author Disclosure Statement}

TB served on advisory boards of Novo Nordisk, Sanofi, Eli Lilly, Boehringer, Medtronic and Bayer Health Care. TB's Institute received research grant support, with receipt of travel and accommodation expenses in some cases, from Abbott, Medtronic, Novo Nordisk, GluSense, Sanofi, Sandoz and Diamyd. TB received honoraria for participating on the speaker's bureaux of Eli Lilly, Bayer, Novo Nordisk, Medtronic, Sanofi and Roch. TB owns stocks of DreamMed.

$\mathrm{BB}$ has interest in Medtronic, Dexcom, and Abbott with research and grant support to his employer. BB receives consultancy fees from Medtronic.

\section{References}

1. Marzelli MJ, Mazaika PK, Barnea-Goraly N, Hershey T, Tsalikian E, Tamborlane W, Mauras N, White NH, Buckingham B, Beck RW, Ruedy KJ, Kollman C, Cheng P, Reiss AL, Diabetes Research in Children Network (DirecNet). Neuroanatomical correlates of dysglycemia in young children with type 1 diabetes. Diabetes 2014; 63: 343-53.

2. Mauras N, Mazaika P, Buckingham B, Weinzimer S, White NH, Tsalikian E, Hershey T, Cato A, Cheng P, Kollman C, Beck RW, Ruedy K, Aye T, Fox L, Arbelaez AM, Wilson D, Tansey M, Tamborlane W, Peng D, Marzelli M, Winer KK, Reiss AL, Diabetes Research in Children Network (DirecNet). Longitudinal assessment of neuroanatomical and cognitive differences in young children with type 1 diabetes: association with hyperglycemia. Diabetes 2015; 64: 1770-79.

3. Dovč K, Bratina N, Battelino T. A new horizon for glucose monitoring. Horm Res Paediatr 2015; 8: 149-56.

4. New JP, Ajjan R, Pfeiffer AF, Freckmann G. Continuous glucose monitoring in people with diabetes: the randomized controlled Glucose Level Awareness in Diabetes Study (GLADIS). Diabet Med 2015; 32: 609-17.

5. Battelino $\mathrm{T}$, Conget I, Olsen B, Schütz-Fuhrmann I, Hommel E, Hoogma R, Schierloh U, Sulli N, Bolinder J, SWITCH Study Group. The use and efficacy of continuous glucose monitoring in type 1 diabetes treated with insulin pump therapy: a randomised controlled trial. Diabetologia 2012; 55: 3155-62.
6. Riveline JP, Schaepelynck P, Chaillous L, Renard E, SolaGazagnes A, Penfornis A, Tubiana-Rufi N, Sulmont V, Catargi B, Lukas C, Radermecker RP, Thivolet C, Moreau F, Benhamou PY, Guerci B, Leguerrier AM, Millot L, Sachon C, Charpentier G, Hanaire H, EVADIAC Sensor Study Group. Assessment of patient-led or physician-driven continuous glucose monitoring in patients with poorly controlled type 1 diabetes using basal-bolus insulin regimens: a 1-year multicenter study. Diabetes Care 2012; 35: 965-71.

7. DeSalvo DJ, Maahs DM, Messer L, Wadwa RP, Payne S, Ly TT, Buckingham BA. Effect of lipohypertrophy on accuracy of continuous glucose monitoring in patients with type 1 diabetes. Diabetes Care 2015; pii: dc151267.

8. Okada K, Hibi K, Gohbara M, et al. Association between blood glucose variability and coronary plaque instability in patients with acute coronary syndromes. Cardiovasc Diabetol 2015; 14: 111.

9. Kuroda M, Shinke T, Sakaguchi K, Otake H, Takaya T, Hirota Y, Sugiyama D, Nakagawa M, Hariki H, Inoue T, Osue T, Taniguchi Y, Iwasaki M, Nishio R, Kinutani H, Konishi A, Hiranuma N, Takahashi H, Terashita D, Hirata $\mathrm{K}$. Effect of daily glucose fluctuation on coronary plaque vulnerability in patients pre-treated with lipid-lowering therapy: a prospective observational study. JACC Cardiovasc Interv 2015; 8: 800-11.

10. Gohbara M, Iwahashi N, Kataoka S, Hayakawa Y, Sakamaki K, Akiyama E, Maejima N, Tsukahara K, Hibi K, Kosuge M, Ebina T, Umemura S, Kimura K. Glycemic variability determined by continuous glucose monitoring system predicts left ventricular remodeling in patients with a first st-segment elevation myocardial infarction. Circ $J$ 2015; 79: 1092-99.

11. Kataoka S, Gohbara M, Iwahashi N, Sakamaki K, Nakachi T, Akiyama E, Maejima N, Tsukahara K, Hibi K, Kosuge M, Ebina T, Umemura S, Kimura K. Glycemic variability on continuous glucose monitoring system predicts rapid progression of non-culprit lesions in patients with acute coronary syndrome. Circ J 2015 [Epub ahead of print]; DOI 10.1253/circj.CJ-14-1226.

12. Sung JF, Kogut EA, Lee HC, Mannan JL, Navabi K, Taslimi MM, El-Sayed YY. Correlation of continuous glucose monitoring profiles with pregnancy outcomes in nondiabetic women. Am J Perinatol 2015; 32: 461-68.

13. Law GR, Ellison GT, Secher AL, Damm P, Mathiesen ER, Temple R, Murphy HR, Scott EM. Analysis of continuous glucose monitoring in pregnant women with diabetes: distinct temporal patterns of glucose associated with large-forgestational-age infants. Diabetes Care 2015; 38: 1319-25.

14. Cypryk K, Bartyzel L, Zurawska-Klis M, Mlynarski W, Szadkowska A, Wilczynski J, Nowakowska D, Wozniak LA, Fendler W. Continuous glucose monitoring in type 1diabetes pregnancy shows that fetal heart rate correlates with maternal glycemia. Diabetes Technol Ther 2015; 17: 619-24.

15. Battelino T, Liabat S, Veeze HJ, Castañeda J, Arrieta A, Cohen O. Routine use of continuous glucose monitoring in 10,501 people with diabetes mellitus. Diabet Med 2015 [Epub ahead of print] DOI 10.1111/dme.12825.

16. Agrawal $\mathrm{P}$, Zhong A, Welsh JB, Shah R, Kaufman FR. Retrospective analysis of the real-world use of the threshold suspend feature of sensor-augmented insulin pumps. Diabetes Technol Ther 2015; 17: 316-19.

17. Bratina N, Shalitin S, Phillip M, Battelino T. Type 1 diabetes in the young: Organization of two national centers in Israel and Slovenia. Zdrav Var 2015; 54: 139-45. 
18. Kropff J, Bruttomesso D, Doll W, Farret A, Galasso S, Luijf YM, Mader JK, Place J, Boscari F, Pieber TR, Renard E, DeVries JH. Accuracy of two continuous glucose monitoring systems: a head-to-head comparison under clinical research centre and daily life conditions. Diabetes Obes Metab 2015; 17: 343-49.

19. Matuleviciene V, Joseph JI, Andelin M, Hirsch IB, Attvall S, Pivodic A, Dahlqvist S, Klonoff D, Haraldsson B, Lind M. A clinical trial of the accuracy and treatment experience of the Dexcom G4 sensor (Dexcom G4 system) and Enlite sensor (guardian REAL-time system) tested simultaneously in ambulatory patients with type 1 diabetes. Diabetes Technol Ther 2014; 16: 759-67.

20. Bailey T, Bode BW, Christiansen MP, Klaff LJ, Alva S. The performance and usability of a factory-calibrated flash glucose monitoring system. Diabetes Technol Ther 2015 [Epub ahead of print]; DOI 10.1089/dia.2014.0378.

21. Wang X, Ioacara S, DeHennis A. Long-term home study on nocturnal hypoglycemic alarms using a new fully implantable continuous glucose monitoring system in type 1 diabetes. Diabetes Technol Ther 2015 [Epub ahead of print]; DOI 10.1089/dia.2014.0375.

22. Mortellaro M, DeHennis A. Performance characterization of an abiotic and fluorescent-based continuous glucose monitoring system in patients with type 1 diabetes. Biosens Bioelectron 2014; 61: 227-31.

23. Yeoh E, Choudhary P, Nwokolo M, Ayis S, Amiel SA. Interventions that restore awareness of hypoglycemia in adults with type 1 diabetes: a systematic review and metaanalysis. Diabetes Care 2015; 38: 1592-609.

24. Choudhary P, Rickels MR, Senior PA, Vantyghem MC, Maffi P, Kay TW, Keymeulen B, Inagaki N, Saudek F, Lehmann R, Hering BJ. Evidence-informed clinical practice recommendations for treatment of type 1 diabetes complicated by problematic hypoglycemia. Diabetes Care 2015; 38: 1016-29.

25. Tansey M, Beck R, Ruedy K, Tamborlane W, Cheng P, Kollman C, Fox L, Weinzimer S, Mauras N, White N, Tsalikian E, for the Diabetes Research in Children Net- work (DirecNet). Persistently high glucose levels in young children with type 1 diabetes. Pediatr Diabetes 2014 [Epub ahead of print]; DOI 10.1111/pedi.12248.

26. Hommel E, Olsen B, Battelino T, Conget I, SchützFuhrmann I, Hoogma R, Schierloh U, Sulli N, Gough H, Castañeda J, de Portu S, Bolinder J, SWITCH Study Group. Impact of continuous glucose monitoring on quality of life, treatment satisfaction, and use of medical care resources: analyses from the SWITCH study. Acta Diabetol 2014; 51: 845-51.

27. Metzger M, Lederhendler L, Corcos A. Blinded continuous glucose monitoring during Yom Kippur fasting in patients with type 1 diabetes on continuous subcutaneous insulin infusion therapy. Diabetes Care 2015; 38: e34-35.

28. Kaplan W, Afandi B. Blood glucose fluctuation during Ramadan fasting in adolescents with type 1 diabetes: findings of continuous glucose monitoring. Diabetes Care 2015; pii: dc151108.

29. Gomez AM, Gomez C, Aschner P, Veloza A, Muñoz O, Rubio C, Vallejo S. Effects of performing morning versus afternoon exercise on glycemic control and hypoglycemia frequency in type 1 diabetes patients on sensor-augmented insulin pump therapy. J Diabetes Sci Technol 2015; 9: 619-24.

30. Sengoku Y, Nakamura K, Ogata H, Nabekura Y, Nagasaka $\mathrm{S}$, Tokuyama K. Continuous glucose monitoring during a 100-km race: a case study in an elite ultramarathon runner. Int J Sports Physiol Perform 2015; 10: 124-27.

31. Jin SM, Kim TH, Oh S, Baek J, Joung JY, Park SM, Cho YY, Sohn SY, Hur KY, Lee MS, Lee MK, Kim JH. Association between the extent of urinary albumin excretion and glycaemic variability indices measured by continuous glucose monitoring. Diabet Med 2015; 32: 274-79.

32. Bode BW, Battelino T. Continuous glucose monitoring in 2014. Diabetes Technol Ther 2015; 17: S12-20.

33. Pickup JC. Banting Memorial Lecture 2014. Technology and diabetes care: appropriate and personalized. Diabet Med 2015; 32: 3-13. 